\title{
The role of physical activity in primary stroke - prevention
}

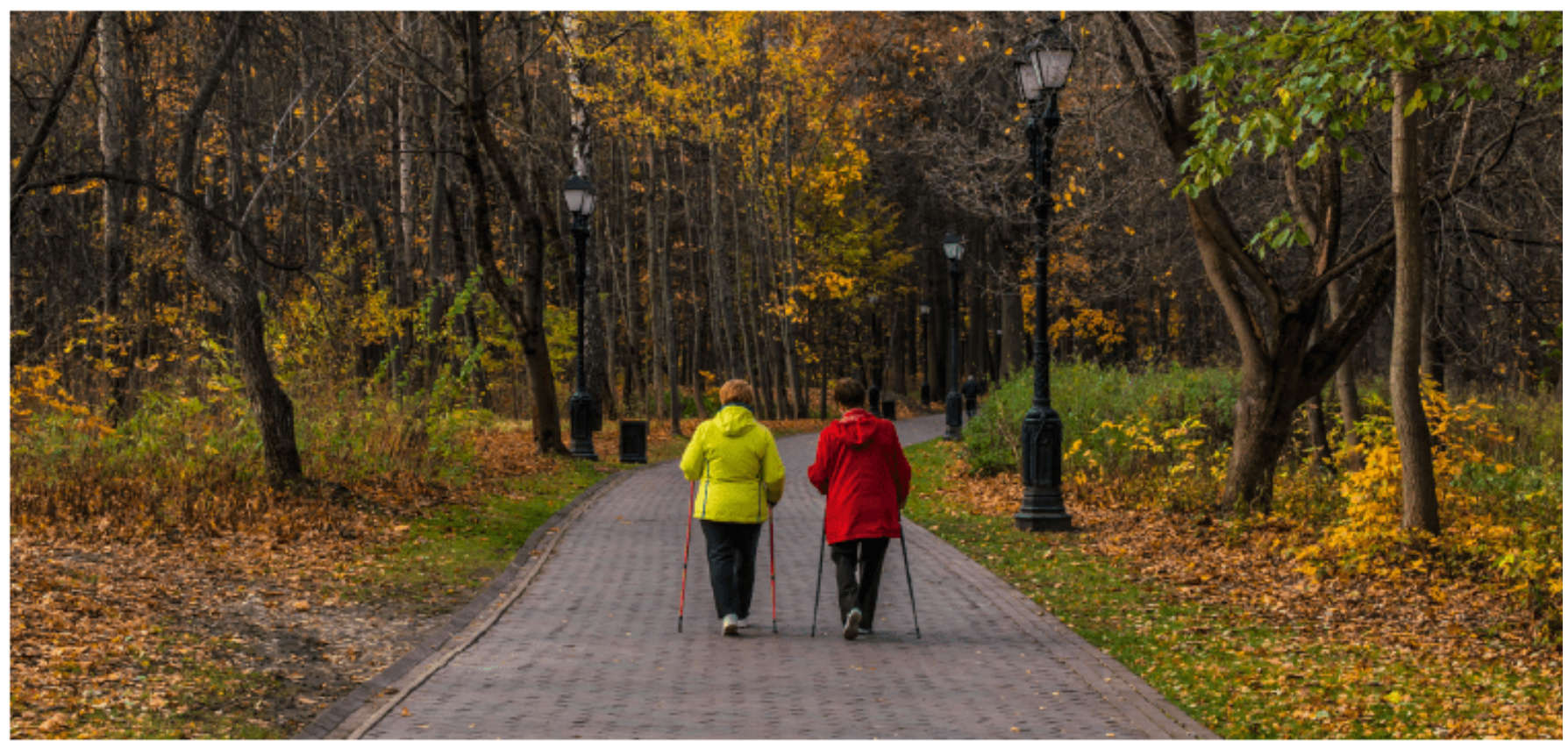

Scutelnic A, Arnold M, Jung S, Heldner MR

Department of Neurology, Inselspital, University Hospital and University of Bern, Bern, Switzerland

\section{Summary}

Physical inactivity is a known risk factor for stroke. The interaction between exercise and risk of stroke is complex. Physical activity has a beneficial effect on most risk factors for stroke, which may show reciprocal potentiation (e.g. obesity, sleep apnea, atrial fibrillation). Advice on physical activity is of importance in primary prevention of stroke. Hereby, type, amount and intensity of physical activity may be distinguished and adjusted according to comorbidities (e.g. in case of heart failure).

\section{Zusammenfassung}

Die körperliche Inaktivität ist ein Risikofaktor für Hirnschlag. Die Zusammenhänge zwischen körperlicher Aktivität und Hirnschlag sind komplex. Die körperliche Aktivität hat einen günstigen Effekt auf die meisten Risikofaktoren für Hirnschlag, welche sich gegenseitig potenzieren können (z.B. Übergewicht, Schlafapnoe, Vorhofflimmern). Eine Beratung hinsichtlich körperlicher Aktivität nimmt in der 
Primärprävention des Hirnschlags einen wichtigen Stellenwert ein. Hierbei können Art, Menge und Intensität der körperlichen Aktivität unterschieden und in Abhängigkeit der Komorbiditäten (z.B. bei Herzinsuffizienz) angepasst werden.

\section{Résumé}

L’inactivité physique est associée avec le risque de développer un accident vasculaire cérébrale (AVC). L'interaction entre l'activité physique et un AVC est complexe. L'activité physique a un effet bénéfique sur la plupart des facteurs de risque pour un AVC, et aussi ces facteurs peuvent s'augmenter réciproquement (par example l'obesité, l'apnée de sommeil et la fibrillation auriculaire). Un conseil concernant l'activité physique est important dans la prévention primaire de l'AVC. Ici, on peut différencier le type, la quantité et l'intensité et adapter ces facteurs en dépendance des comorbidités (par example en cas d'une insuffisance cardiaque).

\section{Introduction}

Physical inactivity is a risk factor for cerebrovascular and cardiovascular disease. [1] First observations concerning reduction of cardiovascular mortality through being physically active were published approximately 65 years ago. [2,3] The studies observed that drivers of double decker buses had fewer cardiovascular events in comparison to more sedentary drivers. It was assumed that these findings were based on the fact, that double decker bus drivers were regularly climbing and descending the bus stairs for selling travel-tickets.

Being physically active improves vascular health by different mechanisms having positive effects on risk factors for stroke. For example, there is a reduction of blood pressure and weight and an improvement of levels of blood lipids and diabetes mellitus type 2. [4]

Physical inactivity has a major socio-economic impact. In the EU, in 2015, the estimated direct costs were 71.1 billion Euro. [1] In Switzerland, in 2013, medical costs attributed to physical inactivity were 0.802 billion Swiss francs (95\%CI 0.684-0.934), 35.4\% of which were attributed to vascular disease (coronary heart disease, stroke and arterial hypertension). [5]

In order to understand the effects of physical activity it is crucial to elucidate its different types and proposed four dimensions. Different types are: endurance, dynamic resistance and isometric resistance training. [6] The proposed four dimensions are: mode (walking, running, cycling etc.), frequency (number of sessions per unit of time), duration and intensity. [7]

Intensity, measured as oxygen consumption, heart reserve rate, stepping rate and/or subjective rating, is classified in absolute, measured by oxygen uptake per unit of time $(\mathrm{ml} / \mathrm{min}$ or $\mathrm{L} / \mathrm{min})$ or by metabolic equivalents (abr. METS), or relative, measured in relation to individual cardiovascular fitness by $\mathrm{VO}_{2} \max$ or percentage of individual maximal heart rate (\%HRmax, which is 220 subtracted by age). [8] Intensity is further classified as follows into: very light, light, moderate, hard, very hard and maximal (table 1). [7] However, these proposed thresholds slightly vary in different studies. Also, quantity of METS/time-unit may be calculated: for example a moderate intensity of 5 METS exerted over 5 minutes would result in 25 METS.

Besides the quantity and intensity of physical activity, the cardiorespiratory fitness or exercise capacity can be used as a marker for vascular mortality. $[9,10]$ The cardiorespiratory fitness is defined as maximal 
oxygen uptake for a given task and is measured in METS and it correlates with the intensity and quantity of physical activity of one individual. [11]

Complex tools, which take the concomitant individual's medication into account, have been developed to facilitate the physician recommending physical activity as a treatment modality. [12] There are different tools accessing vascular risk: AGLA-Score, [13] SCORE-Chart, [14] risk calculator of the American heart and stroke association [15] and the ESC-heart score. [16]

\begin{tabular}{|l|l|l|l|l|}
\hline \multicolumn{2}{|c|}{ relative intensity } & \multicolumn{2}{c|}{ absolute intensity } \\
\hline Intensity & $\mathrm{VO}_{2}$ max & maximal heart rate & intensity & METS \\
\hline very light & $<25 \%$ & $<30 \%$ & sedentary & $1-1.5$ \\
\hline Light & $25-44 \%$ & light & $1.6-2.9$ \\
\hline Moderate & $45-59 \%$ & moderate & $3.0-5.9$ \\
\hline hard & $60-84 \%$ & $50-69 \%$ & vigorous & $>6.0$ \\
\hline very hard & $>85 \%$ & $70-89 \%$ & & \\
\hline maximal & $100 \%$ & $>90 \%$ & & \\
\hline
\end{tabular}

Table 1: Proposed classification of the intensity of physical activity, modified after Strath et al. [7]

\section{Physical activity and risk of stroke overall}

In a meta-analysis of 23 studies (18 cohort, 5 case-control), highly active individuals had a reduction of $25 \%$ (RR $0.75,95 \% \mathrm{CI}, 0.69-0.82, \mathrm{p}=0.001$ ) of risk of stroke compared to individuals with low activity in cohort studies and of $64 \%$ (RR 0.36, 95\%CI, 0.25-0.52, $\mathrm{p}=0.001$ ) in case-control studies. [17] Another meta-analysis of observational studies (31 publications, 24 cohort, 7 case-control) demonstrated a benefit of high intensity physical activity on risk of stroke compared to moderately intense physical activity (RR 0.77, 95\%CI 0.6-0.98) and to inactivity (RR 0.57, 95\%CI 0.43-0.77). [18]

A prospective study ( $n=47,721$, follow-up of 19 years) analyzed the effect of occupational physical activity, leisure time physical activity and commuting on the risk of stroke. Occupational physical activity was defined as physical activity performed at the working place (e.g. sitting office work, standing and walking and lifting or heavy manual labor). Examples for leisure time physical activity are: reading, watching television, walking, cycling, light gardening, running, jogging, swimming, heavy gardening or regular exercise or competitive sports several times per week. The association between occupational activity and risk of stroke was not significant ( $\mathrm{p}=0.060$ ). The HR associated with low, moderate and high leisure time physical activity was $1,0.77$ and 0.63 respectively $(p<0.001)$. The effect remained significant even after adjusting for the major risk factors. Also, commuting protected against stroke: the HRs associated with 0 , $1-29$, and $\geq 30$ minutes of active commuting were $1,0.92$, and 0.89 respectively $(p=0.043)$. [19] The protective effect of physical activity is also evident in advanced age. In a prospective cohort analysis of 4,207 men and women (mean age of 73 years), physical activity was inversely associated with stroke, especially with ischaemic stroke, coronary heart disease and total cardiovascular (fatal or nonfatal myocardial infarction, coronary death or stroke) mortality. This study analyzed walking pace, walking distance/week and leisure time activity and showed that greater values of all these variables are inversely associated with the risk of stroke. [20] 
A prospective cohort study in Japan ( $n=74,913,698,946$ person-years follow up) demonstrated a J-shaped curve concerning the quantity of physical activity (measured in MET-hours per day) for ischaemic stroke. There was highest benefit for the second and third MET-hours/day quartile (5.4 and 13 MET-hours/day respectively). However, although not statistically significant, individuals with levels of activity of $>30-35$ MET-hours/day were likely to have increased risk of subarachnoid haemorrhage. Furthermore, individuals who performed vigorous physical activity (in the 90th percentile, range 18.8-68.4 MET-hours/day) had an increased risk of haemorrhagic stroke. Of note, blood pressure is increasing during physical activity and might be triggering subarachnoid haemorrhage and/or haemorrhagic stroke. [21] A recent meta-analysis of 14 cohort studies with 1,409,340 participants (23,894 strokes) showed an inverse dose-relationship between cardiorespiratory fitness and ischaemic but also haemorrhagic stroke, including subarachnoid haemorrhage, demonstrating that every increment of 5 METS reduces the risk of stroke by 15\% (RR 0.85, 95\%CI 0.79-0.91). [22]

Another meta-analysis included 80 studies with 1,338,143 participants and found a clear inverse doseresponse relationship between all-cause mortality and physical activity. Comparing highest with lowest activity levels for total activity the RR was 0.65 (95\%CI, 0.6-0.71), for leisure activity 0.74 (95\% CI 0.70-0.77), for activities of daily living 0.64 (95\%CI 0.55-0.75) and for occupational activity 0.83 (95\%CI 0.71-0.97). [23] In another prospective study of healthy women $(n=27,055)$ the risk of vascular disease decreased linearly with more physical activity. The investigators studied the impact of physical activity on known risk factors. $59 \%$ of the inverse association turned out to be explained by the favorable effect on known risk factors, with the strongest correlation with systemic inflammation/haemostatic markers (32.6\%) and blood pressure (27.1\%). [24]

\section{Primary stroke prevention overall}

The INTERSTROKE-Study (n=13,447, case-control study, 32 countries) included 10,388 patients with ischaemic stroke and 3,059 with intracerebral haemorrhage and 13,472 controls. The population attributable risk (PAR) of physical activity for stroke turned out to be $35.8 \%$. Regular physical activity, defined as moderate to strenuous activity $\geq 4$ hours/week, reduced the overall risk of (ischaemic and haemorrhagic) stroke (OR 0.41, 95\%CI 0.35-0.48). [25] The same study showed that 10 potentially modifiable risk factors (i.e. arterial hypertension, physical inactivity, dyslipidaemia, unhealthy diet, obesity, psychosocial stress, smoking, cardiac arrhythmia and causes, alcohol overconsumption and diabetes mellitus) were associated with $90 \%$ of the PAR for stroke. [25]

In Switzerland, there were 15,254 hospitalizations because of stroke in 2016. [26] Taking these as well as the data of the INTERSTROKE-Study into account, up to 12-14,000 strokes/year could potentially be prevented in Switzerland. This by optimal management of risk factors for stroke. However, this extrapolation is assuming that the distribution of risk factors between the Swiss population and the patients in the INTERSTROKE-Study is roughly comparable.

\section{Effects of physical activity on risk factors for stroke}

Blood pressure

Arterial hypertension is one of the most important risk factors for stroke. [25] It induces remodeling of the vessel wall, atherosclerosis, disturbed endothelial function and loss of autoregulation. [27] 
The prevalence of high blood pressure increases with age; $26.1 \%$ among those 20-44 years of age and 78.2\% among those $>65$ years of age suffer from arterial hypertension. [4] Advancing age is weakening the association between arterial hypertension and stroke. [28]

There is strong evidence that physical activity has an antihypertensive effect, even in individuals with resistant arterial hypertension. [29,30] The exact mechanisms are still unclear, postulated is an endothelial gain of function, a decrease of inflammation, autonomic modulation, angio- and arteriogenesis, intimamedia thickness and an increase of insulin sensitivity, arterial compliance and luminal diameter. [31] A meta-analysis ( $n=5,223,3,401$ exercise and 1,822 sedentary controls) showed a significant reduction for systolic blood pressure (abr. SBP) after endurance, dynamic resistance and isometric resistance training, but not after combined training. The diastolic blood pressure (abr. DBP) was significantly reduced after endurance, isometric resistance and after combined training. [6]

An intervention study (207 subjects with stage 1 and

2 hypertension, 8-week exercise intervention) has demonstrated a clear relationship between the duration of physical activity per week and blood pressure in people with essential arterial hypertension, with the greatest effect at 61-90 min/week of moderate intensity exercise. Higher duration of physical activity did not seem to be of further benefit. [30]

\section{Dyslipidaemia}

A high Apolipoprotein (Apo) B/ApoA1 ratio is associated with an elevated risk of ischaemic stroke. [25] ApoB are contained in LDL-particles. ApoB-containing particles, including triglycerides and LDL are able to cross the endothelial barrier and may provoke the initiation and subsequent growth of an atheroma. [14] One meta-analysis of prospective studies $(n=352,033$,

2 million person-years) has found a $25 \%$ (95\%CI 13-40\%) increased risk of ischaemic stroke with every increase of the total cholesterol level of $1 \mathrm{mmol} / \mathrm{l}$ on the one hand, but on the other hand a $20 \%(95 \% \mathrm{CI}$ : 8-30\%) decreased risk of fatal haemorrhagic stroke. [32] Cholesterol has an important role in maintaining the membrane integrity [33] and lower levels may trigger vessel-wall rupture.

Physical activity has a favorable effect on plasma lipid levels regardless of the diet and of the body weight. [34] Exercise increases the ability of muscle tissue to take up and oxidize non-esterified fatty acids and increases the activity of lipoprotein lipase in muscles. [35]

A prospective study ( $\mathrm{n}=384$, follow-up duration of 6 months) demonstrated a higher reduction of LDLcholesterol levels the higher the exercise intensity. [34] The group with the highest reduction of LDLcholesterol levels did 20 miles (aprox. $32 \mathrm{~km}$ ) a week at $65-80 \%$ max- $\mathrm{VO}_{2}$ max. Physical activity is supposed to reduce plasma lipid levels through weight loss. [36]

\section{Obesity}

Obesity increases the risk of stroke by increased plasma cholesterol, arterial hypertension, heart disease, diabetes, atrial fibrillation, sleep apnea, psychosocial factors and economic difficulties. [25,37] The favorable effect of physical activity on the body-mass-index (abr. BMI) and waist circumference in morbid obese people is well known. Multiple conducted prospective studies have shown reduced BMI in obese individuals after a period of sustained aerobic and dynamic resistance training. [38] However, a significant difference between high intensity interval/sprint interval training and moderate intensity continuous training has not been found. [39] 
Weight loss is beneficial by decreasing blood pressure, inflammatory markers, LDL-cholesterol and triclycerid levels, by increasing HDL-cholesterol levels and by improving glucose tolerance. [37] The amount of physical activity recommended by the American College of Sports Medicine and current evidence category is presented in table 2. [37]

\begin{tabular}{|c|c|}
\hline Evidence Statement & Evidence Category \\
\hline Physical activity [PA] of $150-250 \mathrm{~min} /$ week will prevent weight gain greater than $3 \%$ in most adults. & A \\
\hline $\begin{array}{l}\text { PA } 150 \mathrm{~min} / \text { week promotes minimal weight loss, PA of } 150 \mathrm{~min} / \text { week results in modest weight loss } \\
\text { of } 2-3 \mathrm{~kg} \text {. PA of } 225-420 \mathrm{~min} / \text { week results in } 5-7.5 \mathrm{~kg} \text { weight loss and a dose-response exists. }\end{array}$ & B \\
\hline $\begin{array}{l}\text { Some studies support a } 200-300 \mathrm{~min} / \text { week PA for weight maintenance to reduce weight regain } \\
\text { after weight loss, and it seems that "more is better". However, there are no correctly designed, } \\
\text { adequately powered, energy balance studies to provide evidence for PA to prevent weight regain } \\
\text { after weight loss. }\end{array}$ & B \\
\hline $\begin{array}{l}\text { Lifestyle PA is an ambiguous term and must be carefully defined to evaluate the literature. Given } \\
\text { this limitation, it seems lifestyle PA may be useful to counter the small energy imbalance respon- } \\
\text { sible for obesity in most adults. }\end{array}$ & B \\
\hline PA will increase weight loss if diet restriction is modest but not if diet restriction is severe. & A \\
\hline $\begin{array}{l}\text { Research evidence does not support resistance training [RT] as effective for weight loss with or } \\
\text { without diet restriction. There is limited evidence that RT promotes gain or maintenance of lean } \\
\text { mass and loss of body fat during energy restriction. }\end{array}$ & B \\
\hline
\end{tabular}

Table 2: Amount of physical activity recommended by the American College of Sports Medicine and current evidence category [38]

\section{Psychosocial stress}

A meta-analysis of 17 prospective studies showed an increase in risk of stroke of 34\% (95\%CI 17-54\%; $\mathrm{p}=0,003$ ) in individuals with depression. [40] Possible explanations are medication malcompliance, unhealthier lifestyle, increased systemic inflammation, associated arterial hypertension, diabetes mellitus and increased platelet activity. [40,41]

Physical inactivity increases the odds of having depression (OR 3.15). [42] In a population-based study $(n=19,288)$ exercisers were less anxious, depressed, neurotic and more extroverted and sensation seeking. [43]

\section{Smoking}

Smoking is associated with increased vascular mortality. In people who smoke, there is a twofold increased risk of ischaemic stroke. [44] Moreover, the risk grows exponentially with more cigarettes smoked per day. [25] Smoking is strongly associated with subarachnoidal haemorrhage (SAH). About 1 in 3 SAHs is attributed to current smoking. Possible mechanisms are increased systemic coagulability, inflammation within arterial walls, increased blood pressure, endothelial dysfunction and degradation of elastin. [45] Moderate to heavy smoking is also associated with intracerebral haemorrhage. However, the association of mild smoking and intracerebral haemorrhage is less clear. [25,46,47] Physical activity has a favorable effect on cigarette craving, prolonging the delay to ad libitum smoking. [48] Smoking cessation is facilitated by physical activity. In an intervention study including female smokers ( $n=236$, medium age 43, medium cigarettes/day 17), physical activity was associated with a higher chance of achieving complete cessation (targeted quit date week 4). [48] For persons who already quitted 
smoking, engaging in physical activity increased the overall-sense of well-being. [50]

Physical activity reduces smoking-induced systemic inflammation by reducing surface markers on T-cells and decreasing inflammatory cytokines and improves the structure and function of muscles by inhibition of catabolism and by stimulating anabolic pathways. [51]

\section{Atrial fibrillation}

Atrial fibrillation is a known risk factor for stroke. [25,52-54]

After analyzing the available evidence, Elliot et al. [55] concluded, that a reduction of approx. $12 \%$ of relative risk of developing atrial fibrillation could be achieved at a dose of approx. 1000-1500 METminutes/week. However, this analysis should be interpreted with caution. In the available studies, quantity of physical activity was self-reported in all and atrial fibrillation in some studies.

In an observational study participants who performed any vigorous physical activity in the upper tertile (i.e. >19.575 MET-minutes/week), showed a reduction of incidence of atrial fibrillation (upper tertile HR 0.46, 95\%CI 0.22-0.98, p=0.045) after adjusting for cigarette smoking, resting heart rate, systolic blood pressure, use of antihypertensives, low density lipoprotein, high density lipoprotein, body mass index, diabetes mellitus and left ventricular hypertrophy. [56]

However, in a cohort-study of 52,755 long-distance cross-country skiers a higher incidence of cardiac arrhythmias, including atrial fibrillation, was observed. [57]

Also, inflammation of the heart tissue and in the systemic circulation is associated with initiation and recurrence of atrial fibrillation. [58] Physical activity reduces the subclinical systemic inflammation, which could have a favorable effect on the incidence of atrial fibrillation. [59] Moreover, obesity is a risk factor for atrial fibrillation through multiple mechanisms such as left atrial enlargement and increased inflammation. Therefore, weight loss achieved through physical activity reduces the incidence, severity and morbidity of atrial fibrillation. [60]

Furthermore, it was shown that physical activity improves the autonomic modulation of cardiac rhythm control. [61] Autonomic dysbalance has a putative role in the genesis of atrial fibrillation. So, the modulation of autonomic balance through physical activity may have a positive effect on incident atrial fibrillation. [62]

Last but not least, in a cohort-study of sleep-clinic patients those with obstructive sleep apnea (defined as AHI $>5 / h$ ) had a two-fold increased risk of incident atrial fibrillation after an average follow-up of 4.7 years. [63] Physical activity has been shown to be a simple to implement treatment option for sleep apnea. [64] Multiple beneficial mechanisms of physical activity on sleep apnea have been postulated which are: increased upper airway dilator muscle tone, reduced fluid accumulation in the neck, increased slow-wave sleep, reduced body weight and reduced systemic inflammatory response. [60,64]

\section{Heart attack}

Although many risk factors for heart attack are the same as for ischaemic stroke, heart attack is an independent risk factor for ischaemic stroke by inducing cardiac arrhythmia and intra-cardiac thrombus formation. [65]

Physical activity has beneficial effects on coronary heart disease by improving heart function, increasing exercise capacity and reducing rate, recurrence and mortality of coronary heart disease. [66] 


\section{Alcohol overconsumption}

Alcohol overconsumption is another risk factor for stroke. [25] A recent meta-analysis $(n=599,912)$ showed that $>100 \mathrm{~g}$ ethanol/week increased the risk of stroke (HR 1.14, 95\%CI 1.10-1.17). [67] Light alcohol consumption is associated with higher HDL-cholesterol levels, reduced platelet-activity, lower fibrinogen concentration and increased insulin-sensitivity, whereas heavy alcohol consumption is associated with arterial hypertension, hypercoagulability, reduced cerebral blood flow and atrial fibrillation. [45]

A survey study with US-participants ( $n=230,856)$ showed a positive correlation between alcohol consumption and physical activity up to a certain upper quantity of alcohol consumed (i.e. light and moderate drinking). However, the probability of a physically active lifestyle decreased with heavy drinking. [68]

A systematic review of 5 studies, which examined the interaction between alcohol consumption disorders and physical activity concluded that alcohol dependence, diagnosed according to DSM IV-criteria, is not related to physical activity. Also, this study speaks about a "ceiling effect”, up to which alcohol consumption is positively associated with physical activity. [69]

There are multiple possible explanations of the apparently paradoxical positive association between alcohol consumption and physical activity: sensation-seeking behavior, socializing and drinking after participation in organized group sports, willing to compensate for the weight gain after drinking by being physically active, especially in women. [70,71]

In experimental studies in mice physical activity as a naturally rewarding activity induced expression of various molecules in mesolimbic reward pathways. The same phenomenon has been observed after illicit drug consumption. [70]

Physical activity is increasingly recognized as a treatment option for alcohol overconsumption. A metaanalysis of 22 prospective studies investigated the effect of physical activity on substance use disorders. 3 studies studied alcohol overconsumption alone and 4 polytoxicomany, including alcohol overconsumption. The studies showed a significant benefit of physical activity on abstinence for alcohol (OR 1.65, 95\%CI 1.14-2.39, $\mathrm{p}=0.0032$ ) regardless of the type, i.e. mind-body exercise (Tai Chi Quan, Qigong and Yoga) or aerobic exercise and intensity. A significant effect of physical activity also has been observed (SMD -0.77 , 95\%CI 1.73-0.19, $\mathrm{p}=0.0165$ ) on the associated depression. A benefit of physical activity in patients with alcohol use disorders, although not statistically significant, was shown for anxiety (SMD -0.21, 95\%CI -0.58-0.16, $\mathrm{p}=0.5975$ ) and withdrawal symptoms (SMD -1.67, 95\%CI -3.51-0.17, $\mathrm{p}=0.399$ ). [72]

\section{Diabetes mellitus}

Diabetes mellitus is a risk factor for stroke. [25] It is associated with arterial hypertension, overweight (diabetes mellitus type 2), dyslipidemia and atrial fibrillation. It causes endothelial dysfunction, thickening of basal membrane and systemic inflammation. [73,74]

The role of physical activity in diabetes mellitus has been described in detail elsewhere. [75]

The evidence of a favorable effect of physical activity on diabetes mellitus type 2 is strong. A meta-analysis of 47 randomized trials $(n=8,538)$ showed that a significant HbA1c reduction can be achieved by structured aerobic, resistance or combined physical activity and that greater HbA1c reduction was observed in the subgroup performing $>150 \mathrm{~min} /$ week of supervised physical activity, without serious adverse effects being reported. High intensity exercise was not associated with significant reduction of HbA1c. The favorable 
effect of physical activity on diabetes mellitus is explained by improved resistance to insulin. [76] However, the benefit of physical activity on diabetes mellitus type 1 is less clear because of an associated potential complication of hypoglycaemia linked to high intensity exercise. The glycemic variability is greater during physical activity. [77] However, knowing the glycemic index of different foods, adapting the required insulin-dose and usage of continuous glucose monitoring, physical activity can be performed safely. [75]

\section{Conclusions}

Even small amounts of physical activity are decreasing the risk of stroke according to one meta-analysis. Authors found a linear relation between the quantity of physical activity and risk for ischaemic stroke. Only very high amounts have been associated with higher risks of subarachnoid haemorrhage and/or haemorrhagic stroke. However, an increase of cardiorespiratory fitness through exercise has been demonstrated not only to protect against ischaemic but also against haemorrhagic stroke in another metaanalysis. Also a dose-response relationship between physical activity and all-cause mortality was found. Physical activity is a simple to implement treatment option in primary prevention of stroke. The INTERSTROKE-Study identified the 10 most relevant potentially modifiable risk factors for stroke: arterial hypertension, physical inactivity, dyslipidaemia, unhealthy diet, obesity, psychosocial stress, smoking, cardiac arrhythmia and causes, alcohol overconsumption and diabetes mellitus. Physical activity has been shown to have beneficial effects on these risk factors. Every patient should get enlighted about this. Current guidelines on primary prevention in stroke prevention recommend moderate to high intensity physical activity in healthy individuals for $40 \mathrm{~min} /$ day, 3-4 days/week. [45] Examples of modes of physical activity include walking, jogging, swimming, cycling, gardening etc. The proposed thresholds for moderate intensity are 3-5.9 METS, $\mathrm{VO}_{2} \max 45-59 \%$ and $\mathrm{HRmax}$ 50-69\% and for high intensity are $>6$ METS, $\mathrm{VO}_{2} \max$ 60-84\%, HRmax 70-89\%.

\section{Korrespondenzadresse}

Adrian Scutelnic

Assistenzarzt

Universitätsklinik für Neurologie

3010 Bern

adrian.scutelnic@insel.ch

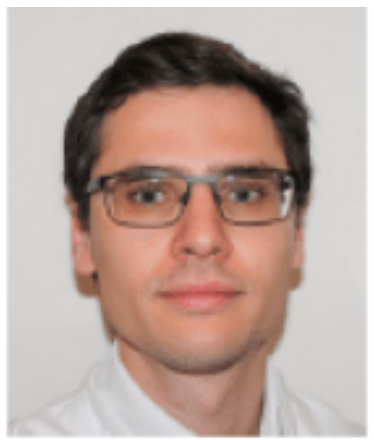


पPD Dr. med. Mirjam R. Heldner, MSc

Oberärztin

Universitätsklinik für Neurologie

3010 Bern

mirjam.heldner@insel.ch

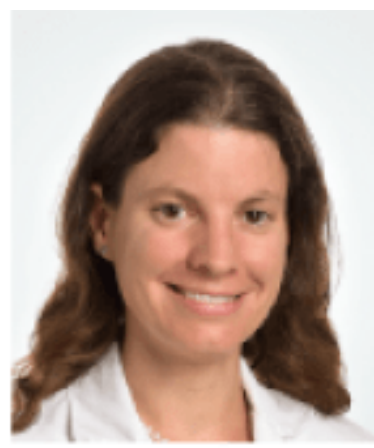

\section{References}

1. Ding D, Kolbe-Alexander T, Nguyen B, Katzmarzyk PT, Pratt M, Lawson KD. The economic burden of physical inactivity: a syste-

matic review and critical appraisal. Br J Sports Med. 2017 Oct;51(19):

1392-1409.

2. Morris JN, Crawford MD: Coronary Heart Disease and Physical Activity of Work, Evidence of a National Necropsy Survey. Br Med J. 1958 Dec 20;2(5111):1485-1496.

3. Heady JA, Morris JN, Kagan A, Raffle PA. Coronary heart disease in London busmen: a progress report with particular reference to physique. Br J Prev Soc Med 1961;15:143.

4. Benjamin EJ, Muntner P, Alonso A, Bittencourt MS, Callaway CW, Carson AP et al. Heart Disease and Stroke Statistics - 2019 Update. A Report From the American Heart Association. Circulation 2019; 139:e56-e528.

5. Mattli R, Wieser S, Probst-Hensch N, Schmidt-Trucksäss A, Schwenkglenks M. Physical inactivity caused economic burden depends on regional cultural differences. Scand J Med Sci Sports. 2019 Jan; 29(1):95-104.

6. Cornelissen VA, Smart NA: Exercise Training for Blood Pressure: A. systematic Review and Metaanalysis. J Am Heart Assoc 2013. 2(1).

7. Srath SJ, Kaminsky LA, Ainsworth BE, Ekelund U, Freedson PS, Gary RA et al. Guide to the Assessment of Physical Activity: Clinical and Research Applications. A Scientific Statement From the American Heart Association. Circulation 2013;128:2259-2279.

8. Piepoli MF, Hoes AW, Agewall S, Albus C, Brotons C, Catapano AL et al. 2016 European Guidelines on cardiovascular disease prevention in clinical practice. Eur J Prev Cardiol 2016;23:NP1-96.

9. 9. Wang Y, Li F, Cheng Y, Gu L, Xie Z. Cardiorespiratory fitness as a quantitative predictor of the risk of stroke: a dose-response meta-analysis. J Neurol. 2019 Nov 4.

10. Gulati M, Black HR, Shaw LJ, Arnsdorf MF, Merz CN, Lauer MS et al. The prognostic value of a nomogram for exercise capacity in women. $\mathrm{N}$ Engl J Med. 2005;353:468-475.

11. Samitz G, Egger M, Zwahlen M. Domains of physical activity and all-cause mortality: systematic review and dose-response meta-analysis of cohort studies. Int J Epidemiol. 2011 Oct;40(5):1382-400.

12. Hansen D, Dendale P, Coninx K, Vanhees L, Piepoli MF, Niebauer J et al. The EAPC Exercise Prescription in Everyday practice \& Rehabilitative Training (EXPERT) tool: a digital training and decision support system for optimized exercise prescription in cardiovascular disease. Concept, definitions and construction methodology. Eur J Prev Cardiol 2017;24(10)1017-1031.

13. https://www.agla.ch/risikoberechnung/agla-risikorechner

14. Mach F, Baigent C, Catapano AL, Koskinas KC, Casula M, Badimon L et al. 2019 ESC/EAS Guidelines for the management of dyslipidaemias: lipid modification to reduce cardiovascular risk. European Heart 
Journal 2019;00,1-78.

15. http://my.americanheart.org/cvriskcalculator

16. https://professional.heart.org/professional/GuidelinesStatements/PreventionGuidelines/UCM_457698_ ASCVD-Risk-Calculator.jsp

17. Lee CD, Folsom AR, Blair SN. Physical activity and risk of stroke: a meta-analysis. Stroke. 2003 Oct;34(10):2475-81.

18. Wendel-Vos GC, Schuit AJ, Feskens EJ, Boshuizen HC, Verschuren WM, Saris WH et al. Physical activity and stroke. A meta-analysis of observational data. Int J Epidemiol. 2004 Aug;33(4):787-98.

19. Hu G, Sarti C, Jousilahti P, Silventoinen K, Barengo NC, Tuomilehto J. Leisure time, occupational, and commuting physical activity and the risk of stroke. Stroke. 2005 Sep;36(9):1994-9. Epub 2005 Aug 4.

20. Soares-Miranda L, Siscovick DS, Psaty BM, Longstreth WT Jr, Mozaffarian D. Physical Activity and Risk of Coronary Heart Disease and Stroke in Older Adults: The Cardiovascular Health Study. Circulation. 2016 Jan 12;133(2):147-55.

21. Kubota Y, Iso H, Yamagishi K, Sawada N, Tsugane S; JPHC Study Group. Daily Total Physical Activity and Incident Stroke: The Japan Public Health Center-Based Prospective Study. Stroke. 2017 Jul;48(7):1730-1736.

22. Wang Y, Li F, Cheng Y, Gu L, Xie Z. Cardiorespiratory fitness as a quantitative predictor of the risk of stroke: a dose-response meta-analysis. J Neurol. 2019 Nov 4.

23. Samitz G, Egger M, Zwahlen M. Domains of physical activity and all-cause mortality: systematic review and dose-response meta-analysis of cohort studies. Int J Epidemiol. 2011 Oct;40(5):1382-400.

24. Mora S, Cook N, Buring JE, Ridker PM, Lee IM. Physical activity and reduced risk of cardiovascular events: potential mediating mechanisms. Circulation. 2007 Nov 6;116(19):2110-8.

25. O’Donnell MJ, Chin SL, Rangarajan S, Xavier D, Liu L, Zhang H et al. Global and regional effects of potentially modifiable risk factors associated with acute stroke in 32 countries (INTERSTROKE): a case control study. Lancet 2016;388:761-75.

26. https://www.bfs.admin.ch/bfs/de/home/statistiken/gesundheit/gesundheitszustand/krankheiten/herzkreislauf-erkrankungen.html

27. Pantoni L. Cerebral small vessel disease: from pathogenesis and clinical characteristics to therapeutic challenges. Lancet Neurol 2010; 9:689-701.

28. Lee M, Saver JL, Chang B, Chang KH, Hao Q, Obviagele G. Presence of baseline prehypertension and risk of incident stroke. Neurology 2011;77:1330-7.

29. Johnson BT, MacDonald HV, Bruneau ML, Goldsby TU, Brown JC, Huedo-Medina TB et al. Methodological quality of meta-analyses on the blood pressure response to exercise: a review. J Hypertens. 2014; 32:706.

30. Ishikawa-Takata K, Ohta T, Tanaka H: How Much Exercise is Required to Reduce Blood Pressure in Essential Hypertensives: A Dose-Response Study. AJH 2003;16:629-633.

31. Diaz KM, Shimbo D: Physical Activity and the Prevention of Hypertension. Curr Hypertens Rep. 2013 Dec;15(6):659-668.

32. Zhang X, Patel A, Horibe H, Wu Z, Barzi F, Rodgers A et al. Asia Pacific Cohort Studies Collaboration. Cholesterol, coronary heart disease, and stroke in the Asia Pacific region. Int J Epidemiol. 2003 Aug;32(4):563-72.

33. Björkhem I, Meaney S: Brain Cholesterol: Long Secret Life Behind a Barrier. Arterioscler Thromb Vasc Biol. 2004;24:806-815.

34. Huffman KM, Hawk VH, Henes ST, Ocampo CI, Orenduff MC, Slentz CA et al: Exercise effects on lipids in persons with varying dietary patterns-does diet matter if they exercise? Responses in Studies of a Targeted Risk Reduction Intervention through Defined Exercise I. Am Heart J. 2012 Jul;164(1):117-24. Obes Rev. 2016 Oct;17(10):1001-11.

35. Eriksson J, Taimela S, Koivisto VA: Exercise and the metabolic syndrome. Diabetologia (1997) 
40:125-135.

36. Zomer E, Gurusamy K, Leach R, Trimmer C, Lobstein T, Morris S et al: Interventions that cause weight loss and the impact on cardiovascular risk factors: a systematic review and meta-analysis. Obes Rev. 2016 Oct;17(10):1001-11.

37. Donnely JE, Blair SN, Jakicic JM, Manore MM, Rankin JW, Smith BK. Appropriate Physical Activity Intervention Strategies for Weight Loss and Prevention of Weight Regain for Adults. Medicine \& Science in Sports \& Exercise 2009. 41(2) - 459-471.

38. Fonseca-Junior SJ, Sá CG, Rodrigues PA, Oliveira AJ, Fernandes-Filho J. Physical Activity and Morbid Obesity: A systematic Review. ABCD Arq Bras Cir Dig 2013;26:67-73.

39. Keating SE, Johnson NA, Mielke GI, Coombs JS. A systematic review and meta-analysis of interval training versus moderate-intensity continuous training on body adiposity. Obes Rev 2017 Aug;18(8):943-964.

40. Dong JY, Zhang YH, Tong, Qin LQ. Depression and Risk of Stroke. A Meta-Analysis of Prospective Studies. Stroke. 2011;43:32-37.

41. Everson-Rose SA, Roetker RS, Lutsey PL, Kershaw KN, Longstreth WT Jr, Sacco RL et al. Chronic Stress, Depressive Symptoms, Anger, Hostility and Risk of Stroke and Transient Ischemic Attack in the MESA Study. Stroke 2014;45(8):2318-2323.

42. Weyer S. Physical inactivity and depression in the community. International Journal of Sports Medicine 1992;13:492-496.

43. De Moor MH, Beem AL, Stubbe JH, Boomsma DI, De Geus EJ. Regular exercise, anxiety, depression and personality: a population-based study. Prev Med. 2006 Apr;42(4):273-9. Epub 2006 Jan 24.

44. Mechia JF, Bushnell C,Boden-Albala B, Brown LT, Bravata DM, Chaturvedi S et al. Guidelines for the Primary Prevention of Stroke. A Statement for Healthcare Professionals From the American Heart Association/American Stroke Association. Stroke 2014;45:3754-3832.

45. Anderson CS, Feigin V, Bennett D, Lin RB, Hankey G, Jamrozik

K. Australasian Cooperative Research on Subarachnoid Hemorrhage Study (ACROSS) Group. Active and passive smoking and the risk of subarachnoid hemorrhage: an international population-based case-control study. Stroke. 2004 Mar;35(3):633-7.

46. Zhang Y, Tuomilehto J, Jousilahti P, Wang Y, Antikainen R, Hu

G. Lifestyle factors on the risks of ischemic and hemorrhagic stroke. Arch Intern Med. 2011 Nov 14;171(20):1811-8.

47. Andersen KK, Olsen TS, Dehlendorff C, Kammersgaard LP. Hemorrhagic and ischemic strokes compared: stroke severity, mortality, and risk factors. Stroke. 2009 Jun;40(6):2068-72.

48. Kurti AN, Dalleri J. Effects of exercise on craving and cigarette smoking in the human laboratory. Addict Behav. 2014 Jun;39(6):1131-7.

49. De Jesus S, Prapavessis H. Smoking behaviour and sensations during the pre-quit period of an exercise-aided smoking cessation intervention. Addict Behav. 2018 Jun;81:143-149.

50. Bloom EL, Minami H, Brown RA, Strong DR, Riebe D, Abrantes AM. Quality of Life After Quitting Smoking and Initiating Aerobic Exercise. Psychol Health Med. 2017 Oct;22(9):1127-1135.

51. Krüger K, Seimetz M, Ringseis R, Wilhelm J, Pichl A, Couturier A et al. Exercise training reverses inflammation and muscle wasting after tobacco smoke exposure. Am J Physiol Regul Integr Comp Physiol. 2018 Mar 1;314(3):R366-R376.

52. Kannel WB, Benjamin EJ. Status of the epidemiology of atrial fibrillation. Med Clin North Am 2008;92:17-40,ix.

53. Marini C, De Santis F, Sacco S, Russo T, Olivieri L, Totaro R et al. Contribution of atrial fibrillation to incidence and outcome of ischemic stroke: results from a population-based study. Stroke 2005; 36:1115-1119.

54. Benjamin EJ, Wolf PA, D’Agostino RB, Silbershatz H, Kannel WB, Levy D. Impact of atrial fibrillation 
on the risk of death: the Framingham Heart Study. Circulation 1998; 98:946-952.

55. Elliot AD, Maatman B, Emery MS, Sanders P. The role of exercise in atrial fibrillation prevention and promotion: Finding optimal ranges for health. Heart Rhythm 2017;14:1713-1720.

56. Bapat A, Zhang Y, Post WS, Guallar E, Soliman EZ, Heckbert SR et al. Relation of physical activity and incident atrial fibrillation (from the Multi-Ethnic Study of Atherosclerosis). Am J Cardiol 2015; 116:883-888.

57. Andersen K, Farahmand B, Ahlbom A, Held C, Ljunghall S, Michaelsson K et al. Risk of arrhythmias in 52755 long-distance cross-country skiers: a cohort study. EuropeanHeart Journal (2013) 34,3624-3631.

58. Hu YF, Chen YJ, Lin YJ, Chen SA. Inflammation and the pathogenesis of atrial fibrillation. Nature Reviews Cardiology volume 12, pages 230-243 (2015).

59. Tir AMD, Labor M, Plavec D. The effects of physical activity on chronic subclinical systemic inflammation. Arh Hig Rada Toksikol. 2017 Dec 20;68(4):276-286.

60. Lavie CJ, Pandey A, Lau DH, Alpert MA, Sanders P. Obesity and Atrial Fibrillation Prevalence, Pathogenesis, and Prognosis: Effects of Weight Loss and Exercise. J Am Coll Cardiol. 2017 Oct 17;70(16):2022-2035.

61. Sarmento AO, Wang Y, Qian Y, Smerin D, Zhang S, Zhao Q et al. Newly Detected Atrial Fibrillation after Acute Stroke: A Narrative Review of Causes and Implications. Cardiology. 2019 Oct 10:1-10.

62. Wang Y, Qian Y, Smerin D, Zhang S, Zhao Q, Xiong X. Newly Detected Atrial Fibrillation after Acute Stroke: A Narrative Review of Causes and Implications. Cardiology. 2019 Oct 10:1-10.

63. Gami AS, Hodge DO, Herges RM, Olson EJ, Nykodym JN, Kara T et al. Obstructive Sleep Apnea, Obesity, and the Risk of Incident Atrial Fibrillation. J Am Coll Cardiol. 2007 Feb 6;49(5):565-71.

64. Andrade FM, Petrosa RP. The role of physical exercise in obstructive sleep apnea. J Bras Pneumol. 2016 Nov-Dec;42(6):457-464.

65. Witt BJ, Ballman KV, Brown RD Jr, Meverden RA, Jacobsen SJ, Roger VL. The incidence of stroke after myocardial infarction: a meta- analysis. Am J Med 2006;119:354.e1-354e9.

66. Wang L., Ai D., Zhang N. (2017) Exercise Benefits Coronary Heart Disease. In: Xiao J. (eds) Exercise for Cardiovascular Disease Prevention and Treatment. Advances in Experimental Medicine and Biology, vol 1000. Springer, Singapore, PP 4-6.

67. Wood AM, Kaptoge S, Butterworth AS, Willeit P, Warnakula S, Bolton T et al. Risk thresholds for alcohol consumption: combined analysis of individual-participant data for 599912 current drinkers in 83 prospective studies. Lancet 2018;391:1513-23.

68. French M, Popovici I, Maclean JC. Do Alcohol Consumers Exercise More? Findings from a National Survey. Am J Health Promot. 2009 Sep-Oct;24(1):2-10.

69. Vancampfort D, De Hert M, Stubbs B, Soundy A, De Herdt A, Detraux J et al. A systematic review of physical activity correlates in alcohol use disorders. Arch Psychiatr Nurs. 2015 Aug;29(4):196-201.

70. Wallace DL, Vialou V, Rios L, Carle-Florence TL, Chakravarty S, Kumar A et al . The influence of DeltaFosB in the nucleus accumbens on natural reward-related behavior. J Neurosci. 2008 Oct 8;28(41): 10272-7.

71. Davis HA, Riley EN, Smith GT, Milich R, Burris JL. Alcohol use and strenuous physical activity in college students: A longitudinal test of 2 explanatory models of health behavior. J Am Coll Health. 2017 Feb-Mar;65(2):112-121.

72. Wang D, Wang Y, Wang Y, Li R, Zhou C. Impact of physical exercise on substance use disorders: a meta-analysis. PLoS One. 2014 Oct 16;9(10):e110728.

73. Chen R, Ovbiagele B, Feng W. Diabetes and Stroke: Epidemiology, Pathophysiology, Pharmaceuticals and Outcomes. Am J Med Sci 2016; 351(4):380-386.

74. Benjamin EJ, Levy D, Vaziri SM, D’Agostino RB, Belanger AJ, Wolf PA. Independent risk factors for atrial fibrillation in a population-based cohort. The Framingham Heart Study. Jama 1994;271:840-4.

75. Melmer A, Kempf P, Laimer M. The role of physical exercise in obesity and diabetes. Praxis (Bern 
1994). 2018 Aug;107(17-18):971-976.

76. Umpierre D, Ribeiro PA, Kramer CK, Leitão CB, Zucatti AT, Azevedo MJ et al. Physical activity advice only or structured exercise training and association with HbA1c levels in type 2 diabetes: a systematic review and meta-analysis. JAMA 2011;305:1790-1799.

77. Diaz KM, Shimbo D. Physical Activity and the Prevention of Hypertension. Curr Hypertens Rep. 2013 Dec;15(6):659-668. 